\title{
Improvement of Store Atmosphere and Application of Offline Advertising Strategy Through Business Coaching
}

\author{
Joko Suryo Sumbodo ${ }^{1}$, Anton Wachidin Widjaja ${ }^{2}$ \\ \{jokosuryosumbodo@gmail.com ${ }^{1}$, antonwachidinwidjaja@gmail.com²
}

Magister of Management, Faculty of Economy and Business, University of Indonesia, Jakarta ${ }^{1}$, Management Department, Faculty of Economy and Business, University of Indonesia, Jakarta ${ }^{2}$

\begin{abstract}
In Indonesia, Micro, Small and Medium Enterprises (MSMEs) are of the drivers of the economy. This paper conducted by a series of structured interviews with the owners of BING KOPI SMEs and writer observations, an MSMEs that engaged in the field of Food and Beverages especially in the form of coffee located in Jakarta. This study also conducted through the business coaching process, where the coach helps coachee (SME owner) to find and implement strategies to solve its current problems. The finding shows the problem that BING KOPI SMEs currently faced is a lack of potential customer interest in visiting the outlet. This problem can be solved by implementing several solutions which are associated with improvement of Store Atmosphere, and application of offline advertising in the form of flyers. This research uses the Business Model Canvas Analysis methodology, SWOT Analysis, TOWS Analysis, and Gap analysis.
\end{abstract}

Keywords: Business Coaching, Micro Small and Medium Enterprises, Store Atmosphere, Offline Advertising

\section{Introduction}

Based on reports from the Indonesian Ministry of Cooperatives and SMEs (2018), MSMEs have a share of around $99.99 \%$ (59.2 million units) of the total number of business operators in Indonesia (2018) having increased compared to 2013, which amounted to 57.8 million MSME units, while large businesses are only $0.01 \%$ or around 5000 units. This MSME absorbs around 104.6 million workers $(88.9 \%)$, Small Businesses 5.57 million $(4.73 \%)$, and Medium Enterprises 3.95 million (3.36\%); while Large Enterprises absorbed around 3.54 million people. This means that in combination the SMEs absorb about $97 \%$ of the national workforce, while Large Enterprises only absorb around 3\% of the total national workforce.

The increasing number of MSMEs, the competition will also increase. Every entrepreneur must be able to maintain and develop his market, both old and new consumers, so that profits can increase and these consumers do not move to competitors. But this is not easy. Good marketing strategies and marketing aids are needed in order to retain old customers and get new customers. Many MSME owners also do not have good marketing competence and work alone, so that they have difficulty in running a business. However, MSME owners still have to do marketing for their business growth even though they do not have the resources or operational structures that support those of large companies [1].

BING KOPI is a SME that is engaged in the Food and Beverages industry. This SME offers the manufacture of drinks, especially coffee. Products sold are divided into five types, 
namely, traditional coffee, manual brew, espresso based, flavored coffee, and non-coffee. The main target consumers of BING KOPI are B2C (Business to Consumen) consumers, especially students from various backgrounds ranging from high school students to students in the Utan Kayu and surrounding areas such as rawamangun and Pramuka. Because the products offered are quite diverse, the prices offered are affordable for the target consumers, and also the concept of the booth that is carried is unique and interesting as many elements that express the character of BING KOPI make potential consumers of BING KOPI will continue to exist and increase.

In B2C marketing, BING KOPI wants to present an interesting store atmosphere and in accordance with the philosophy carried by Muhammad Ilham as the owner of BING KOPI that is "There is Coffee, Let's Discuss" by giving a harmonious appearance. Based on the statement from the owner, there are several problems faced by SMEs, including the appearance of the store because of some obstacles such as limited costs and the ability of the owner so that it has an impact on marketing channels that cannot be done optimally.

According to Fauzi [2], Store atmosphere statistically has no direct positive effect on purchase intention depending on the type of business being undertaken, however, store atmosphere has a statistically significant positive effect on service quality in certain types of business, so that the effect store atmosphere to purchase intention is mediated by service quality. Service quality statistically has a positive effect on purchase intention in the food \& beverage and retail businesses, because the business character of this industry is closely related to the quality of products and services provided to customers, as well as other supporting facilities.

This paper aims to offer a new perspective on how enterprise in the food and beverages industry can have better competitive advantage with the the application of a good and attractive store atmosphere, in order to attract more customers on selected segments to gain more profit. In addition, BING KOPI can carry out various marketing communications such as offline advertising to attract new customers.

\section{Literature Review}

In this paper we use several analyzes such as Business Model Canvas (BMC), BING KOPI's strengths and weaknesses analysis with SWOT and TOWS analysis, and Gap analysis. The final stage in this research is a business coaching process carried out by providing proposed solutions to the problems currently faced by BING KOPI.

\subsection{Business Model Canvas (BMC)}

Business Model Canvas is a conceptual tool that consists of related elements that can describe the basic logic of a company's business specifically, create, market and deliver value to generate and create revenue in a sustainable manner [3]. This business model will help everyone to be able to understand the direction and goals of a business which will also be influential in terms of strategic planning so as not to compete in order to be able to survive in the business environment. 
Table 1. Business Model Canvas BING KOPI

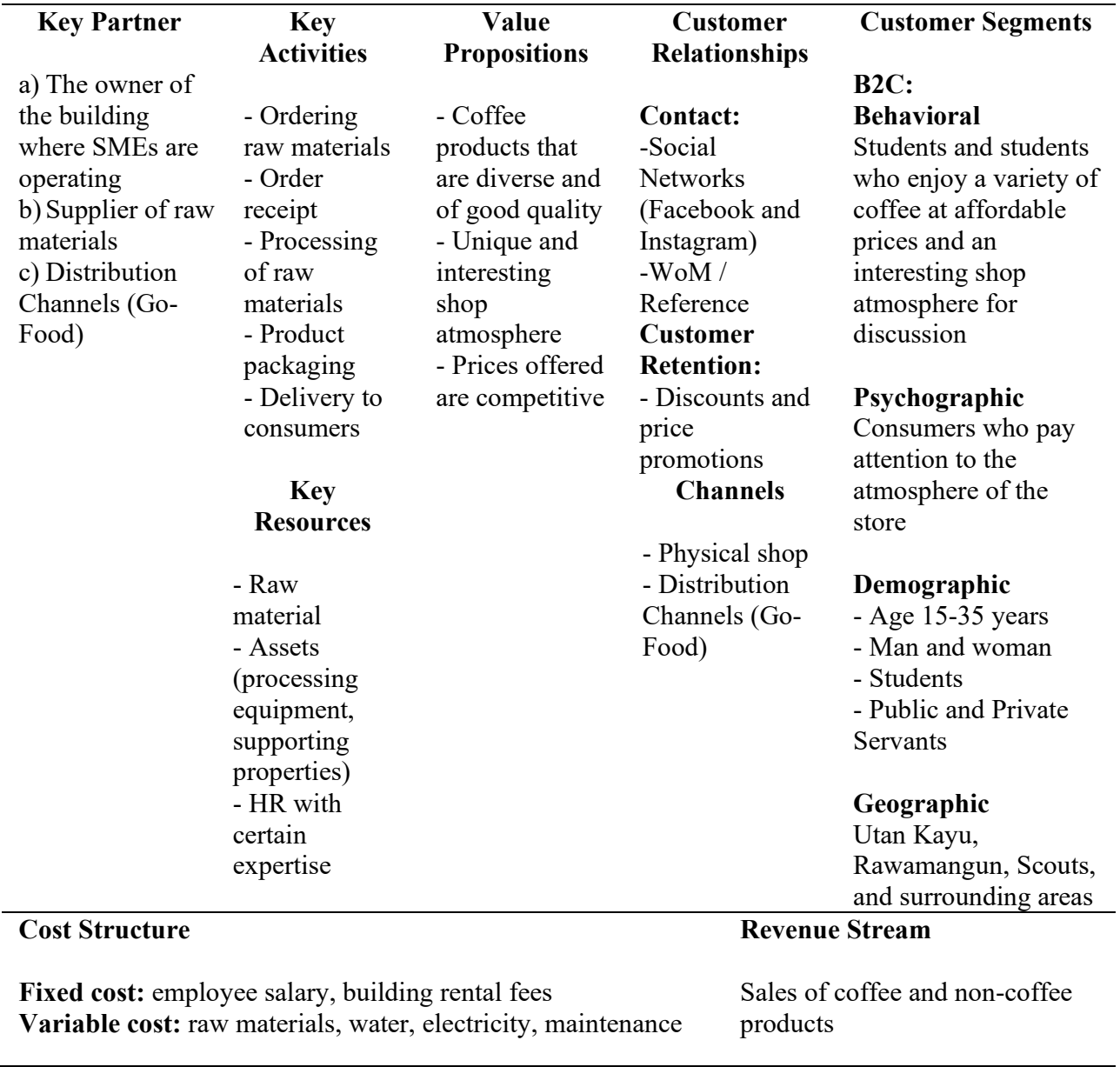

\subsection{SWOT Analysis}

SWOT analysis is used to analyze the internal state of a business unit. SWOT analysis is a measuring tool to analyze the situation inside in the form of strengths or weaknesses or weaknesses of a business unit, as well as outside conditions in the form of opportunities or threats and threats or threats to a business unit [4]. An effective SWOT analysis can be used to plan appropriate management strategies within a company.

Table 2. SWOT Analysis BING KOPI

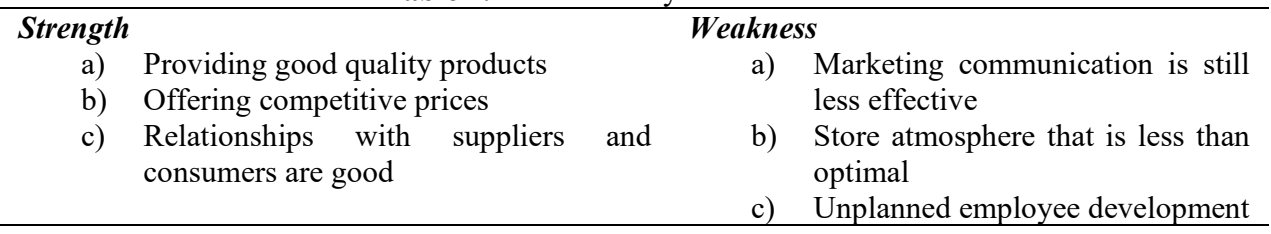




\begin{tabular}{ll}
\hline Opportunity & Threats \\
a) The market potential is still broad, such & a) Variative substitute products \\
as schools and universities around & c) Intense competition \\
UMKM that have not been achieved. & d) External factors from the \\
b) The trend of increasing use of social & $\begin{array}{l}\text { government and global that are } \\
\text { sometimes detrimental } \\
\text { networks. }\end{array}$
\end{tabular}

\subsection{TOWS Analysis}

To complete the previous analysis, we also conducted a TOWS analysis. This analysis can be used to develop the strategies needed by MSMEs. There are four types of strategies namely SO (Strengths-Opportunities) strategy, ST (Strengths-Threats) strategy, WO (WeaknessOpportunities) strategy, WT (Weakness-Threats) strategy.

Table 3. TOWS Analysis BING KOPI

\begin{tabular}{|c|c|c|}
\hline & Strength & Weakness \\
\hline & $\begin{array}{l}\text { S1: Providing good } \\
\text { quality products } \\
\text { S2: Offering competitive } \\
\text { prices } \\
\text { S3: Relationships with } \\
\text { suppliers and consumers } \\
\text { are good }\end{array}$ & $\begin{array}{l}\text { W1: Store Atmosphere that is less } \\
\text { than optimal } \\
\text { W2: Marketing communication is } \\
\text { still ineffective } \\
\text { W3: } \\
\text { Unplanned employee development }\end{array}$ \\
\hline Opportunity & Strength-Opportunity & Weakness-Opportunity \\
\hline $\begin{array}{l}\text { O1: The market } \\
\text { potential is still } \\
\text { wide, such as } \\
\text { schools and } \\
\text { universities } \\
\text { around UMKM } \\
\text { that have not been } \\
\text { achieved. } \\
\text { O2: Trend of } \\
\text { increasing use of } \\
\text { social networks. }\end{array}$ & $\begin{array}{l}\text { - Market potential can } \\
\text { still be expanded to } \\
\text { reach more regions } \\
\text { while still providing } \\
\text { good quality products at } \\
\text { competitive prices (S1, } \\
\text { S2, S3, O1) }\end{array}$ & $\begin{array}{l}\text { - Improving store atmosphere to } \\
\text { make it more attractive to consumers } \\
\text { (W1, O1) } \\
\text { - Add marketing communications in } \\
\text { the form of Offline advertising (W2, } \\
\text { O1, O2) } \\
\text { - HR Development to improve skills. } \\
\text { (W3, O1) }\end{array}$ \\
\hline Threat & Strength-Threat & Weakness-Threat \\
\hline $\begin{array}{l}\text { T1: Varied } \\
\text { substitute products } \\
\text { T2: Tight } \\
\text { competition } \\
\text { T3: External factors } \\
\text { from the } \\
\text { government and } \\
\text { globally which are } \\
\text { sometimes } \\
\text { detrimental }\end{array}$ & $\begin{array}{l}\text { - Keep prices } \\
\text { competitive and develop } \\
\text { skills to make products } \\
\text { more varied (S2, T1, } \\
\text { T2) } \\
\text { - Relationships with } \\
\text { suppliers and consumers } \\
\text { must be maintained (S3, } \\
\text { T3) } \\
\text { - Looking for alternative } \\
\text { raw materials with the } \\
\text { same quality but lower } \\
\text { prices (S2, T3) }\end{array}$ & $\begin{array}{l}\text { - Improvements to store atmosphere } \\
\text { need to be implemented (W1, T3) } \\
\text { - The addition of marketing } \\
\text { communications in the form of } \\
\text { Offline advertising. (W2, T1, T2, T3) }\end{array}$ \\
\hline
\end{tabular}




\subsection{GAP Analysis}

Gap analysis can be used to evaluate business performance [5]. In the planning and work evaluation stages, gap analysis can also be a very important step. This method is most commonly used in the management of an institution's internal management.

To facilitate the problem-solving process from the results of the GAP analysis that has been done, it is necessary to set priorities for each problem. This analysis is used by sorting the problem that need to solve first, by using the Pareto analysis the higher calculation gives priority value to each problem. Grading uses a scale of 1 which is the most difficult to implement up to 10 that are the easiest to do. Similarly, for some components that use a scale of 1 to 10 based on the level of significance.

Table 4. GAP Analysis BING KOPI

\begin{tabular}{clccccc}
\hline No. & \multicolumn{1}{c}{ Indicator } & Score & Quality & $\begin{array}{c}\text { Contribut } \\
\text { ion }\end{array}$ & $\begin{array}{c}\text { Distributi } \\
\text { on }\end{array}$ & Accumulation \\
\hline 1 & Store Atmosphere & 10 & 9 & 90 & $42.5 \%$ & $42.5 \%$ \\
2 & Offline advertising & 8 & 7 & 56 & $26.5 \%$ & $69 \%$ \\
3 & Content marketing & 6 & 6 & 36 & $16.9 \%$ & $85.9 \%$ \\
4 & HR Training & 5 & 6 & 30 & $14.1 \%$ & $100 \%$ \\
\hline & Total & & & 212 & $100 \%$ & \\
\hline
\end{tabular}

\section{Method}

In conducting business coaching research methodology, a framework is needed as guide in doing this research study. The framework start from data collection for the final activity in the business coaching. The aim of this study is in an action plan form results. The first process of business coaching research study is start from interview with the owner. The second process is do the direct observation to the BING KOPI store. And the last process is about the discussion with the owner about the problem that occurs in BING KOPI and how to solve them. Based on data obtained in Business Coaching activities, it will be analyzed using qualitative analysis methods where the data obtained is data analysis in the form of words that are guided by standard procedures. The purpose of qualitative analysis is to parse, discuss, and explain the meaning of a pattern or motif from the results of the interview [6]. Based on the analysis from the previous section, this research will focus on the improvement of store atmosphere which will lead to attracting more customer in order to increase sales. In addition, BING KOPI can carry out various marketing communications such as offline advertising to attract new customers.

To improve the store atmosphere of BING KOPI, the elements should be properly selected to be in accordance with the wishes of the owner and also in accordance with existing resources SMEs have, store atmosphere is a combination of combinations and physical characteristics of a store, space or place such as architectural style, layout, lighting, color, temperature, music, fragrance and other display objects that together can make certain impressions in the minds of customers. [7] . Marketing communication such as implementing offline advertising in the form of flyers which according to Ladd [8] posters and flyers can be 
a useful tool for communicating with new or existing customers. Both media are printed on a sheet that is intended to be distributed in public places and are often used to support promotions such as new products or services, special sales or upcoming events. The final result of this business coaching case study research will be improve the existing store atmosphere with some of the elements that have been discussed to fit the concept of the store, which is narrative cafe with rustic design, so it can attract consumers to visit the store and is expected to make a purchase. In addition marketing communication in the form of offline advertising in the form of a flyer aims as a promotional tool to make marketing communication efficient and appropriate targeting the target segment to be addressed, namely schools and universities in the area around BING KOPI.

\section{Result And Discussion}

\subsection{Store Atmosphere}

According to Berman [7] there are several elements in the store atmosphere which are a combination of combinations and physical characteristics of the store, space or place such as architectural style, layout, lighting, color, temperature, music, fragrance, fragrance and other display objects which together can be make a certain impression in the customer's mind. The first process is the actual store atmosphere observation by coach visiting the physical booth of BING KOPI directly located at Jalan Tirta Sari number 1, Utan Kayu, East Jakarta.

After seeing the actual store atmosphere conditions of the BING COFFEE, the next step is to create a store atmosphere design by planning with the SME owners for the time that can be done in improving the store atmosphere and strengthening the concepts that the SME owners want to carry and adjusting to the existing theories about the components required components

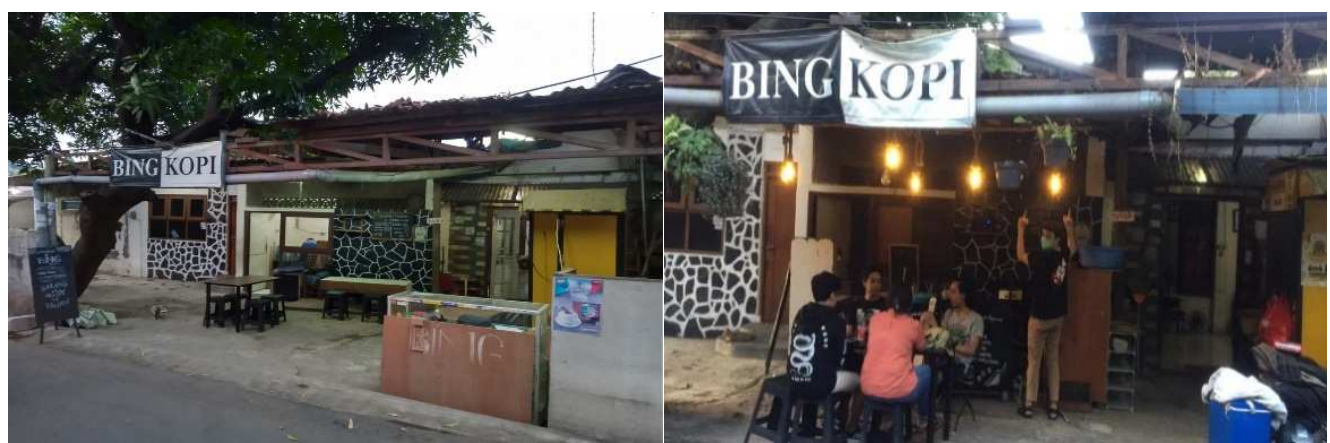

Fig.1. Before and After Improvement of Store Atmosphere

Some elements were improved in this stage where the selection of these elements was based on the ability possessed by MSMEs both from the financial aspect to the time aspect available in the implementation of business coaching. The elements that are fixed at this stage are as follows:

a) Exterior

On the exterior of the shop there are several aspects that are improved including:

- Marquee 
Marquee is a place to display company symbols, signs, names or logos. Marquee can also be made with several combinations of shapes, colors and lighting to make it look attractive. For the logo of the BING COFFEE located in front of the booth, but the absence of lighting on the logo makes the logo invisible at night so lighting is needed in the form of a spotlight. Improvement focus on the logo of the BING COFFEE located in front of the outlet, lighting is made with pre-installed spotlights so that the logo can be seen at night.

1. Visibility

Is a visibility or area of vision can influence consumers in deciding whether they will visit or not. At BING COFFEE, the location of outlets that are located tends to decrease from the highway so it cannot be seen from far away. Therefore we need a clue that there are coffee outlets when viewed from a distance both in the form of information boards and so forth. By adding a sign that says BING COFFEE, open it with various posts so that the store's presence can be seen from the highway.

2. Uniqueness

The uniqueness was created to be able to make the difference and features of a similar store / exterior, so that it is expected to be able to increase the attractiveness of consumers inherent in the minds and memories of consumers. Based on direct observations and interviews with coaches, BING KOPI wants to offer a unique and attractive store atmosphere in accordance with the characteristics of MSMEs. Because BING COFFEE wants to offer a unique and attractive store atmosphere in accordance with the characteristics of MSMEs namely narrative cafe with a rustic design concept.

b) General Interior

Aspects of the General Interior that were improved include:

1. Lighting

Consumer perception can be created with lighting in the room and lighting of the products on display. Proper lighting will make the room comfortable and create an attractive product display. In BING COFFEE, lighting only comes from one source, the LED lights are located in the middle so that at night there are several points in the outlets that are not properly illuminated. Therefore, it is necessary to improve the lighting aspect by adding lights at some points that are not illuminated properly with warm white / yellow color arrangement to give a warm impression to have discussions like the concept that you want to carry. By installing LED lights at each point so that lighting is spread evenly in every corner of the outlet and also the selection of warm white / yellow colors to give a warm impression to carry out discussions such as the concept to be carried. In addition, the use of lights with a rope model makes the impression of a retro classic shop which is also a concept that wants to be carried by the coachee.

\section{Fixture}

The placement of supporting equipment for forming the atmosphere must be done appropriately, the equipment has different characters and shapes, so that its placement will also produce a different atmosphere. Supporting equipment for the operation of BING COFFEE is located in the booth so it cannot be seen by consumers but based on the coachee's statement, the placement of supporting equipment should be visible to consumers according to the store atmosphere that they want to do. The improvement are supporting equipment for the operation of the BING COFFEE is placed in the middle of the outlet so that it can be seen by consumers according to the 
store atmosphere you want to do. The room that was previously used for supporting equipment becomes an additional indoor / indoor space for incoming customers.

\section{Temperature}

Consumer moods can also be affected by temperature. Temperature that is too hot or too cold will disrupt consumer comfort. So it is necessary to condition a comfortable temperature for consumers. The temperature of BING COFFEE is based on observations and interviews with coaches and consumers classified as hot, especially when the store is full so it needs air conditioning such as fans and so on. To regulate the temperature, a number of fans are added to the indoor / outdoor or outdoor / outdoor rooms of the BING COFFEE outlet so that the temperature can remain cool even when the booth is full.

\section{Dead areas}

Dead area is a certain area in the room where product displays cannot be placed such as for example the corner of a room or toilet. So creativity is needed so that the room does not appear to be empty by placing certain ornaments or displays. In BING COFFEE, there is no limit on each corner of the booth making the display appear empty so that a certain display is needed which makes the outlet not appear empty as well as a barrier at each corner of the outlet. Added a few ornamental plants placed at each corner of the booth so that the appearance of the booth does not appear to be empty as well as a divider and also makes the perception of the booth look alive and fresh.

\subsection{Offline Advertising}

This stage discusses the implementation of offline advertising in the form of flyers which according to Ladd [7] posters and flyers can be a useful tool for communicating with new or existing customers. Both media are printed on a sheet that is intended to be distributed in public places and are often used to support promotions such as new products or services, special sales or upcoming events. Here are flyer designs that will be used for offline advertising:

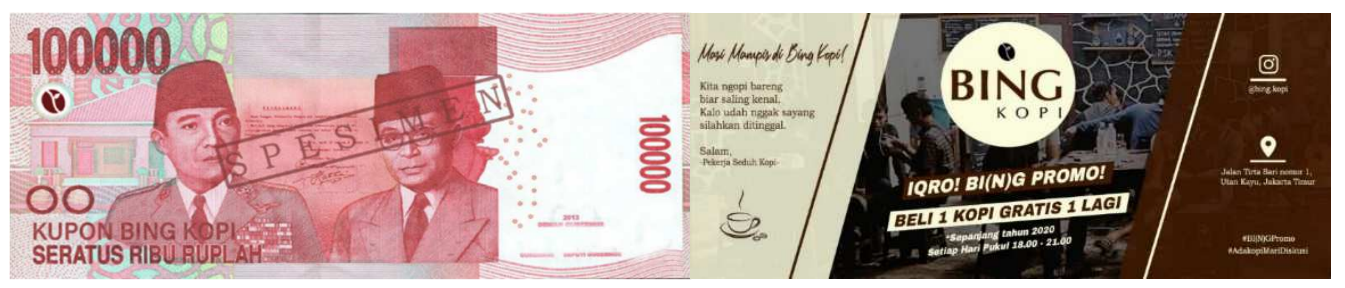

Fig. 2. Applicaition of Offline Advertising

For the criteria of the design of the flyer to be made include several considerations so that the flyer can work effectively according to Ladd [8], as follows:

a) Keep-It-Simple Principle

Keep the design simple with headlines, offers and calls to action. Set a goal for using posters or leaflets, and make sure that every element on the page supports the idea. The design of the flyer is made as simple as possible but still shows the purpose of the flyer and also the characteristics possessed by BING COFFEE. 
b) Size

Although large posters can be made easily, sometimes smaller posters are better at delivering information. In other words, the size to be chosen depends on the purpose of the flyer, for example promotional coupons should use a small size that can be carried easily. Because the purpose of this flyer is as a promotional coupon, the size is also made small, which is $15 \mathrm{~cm} \times 7 \mathrm{~cm}$ like Rp 100,000 denomination.

c) Type

Use large, clear fonts that are easy to read and easy to understand from near and far. The type of font or font used in communication media can make a big difference in the results to be achieved and limit the design to no more than three types of fonts. The use of fonts is divided into 3 , i.e., fonts for the tagline, header content, and content of the promotional coupon.

d) Color

Communication must be easy to read from a distance. Colors that can be easily read from a distance include white on red, black on yellow, dark blue on white, green on white and black on white. In addition, the use of certain colors to show the characteristics of a company can be an additional value in color choices. The color chosen for the front design is red and white according to the $\mathrm{Rp} 100,000$ denomination and for the front design the combination of beige and brown colors is in accordance with the characteristics of the BING COFFEE itself.

e) Illustration

The image or illustration chosen must be carefully so that it can effectively communicate the message to the reader, rather than using words. Additionally graphic images are more suitable for flyer communication because they provide high contact so they can quickly attract attention. The picture or illustration used for the front design is like a Rp. 100,000 denomination in which the aim is to give the impression of a high initial interest when given to the intended target consumer. In addition, the selection of designs such as Rp. 100,000 denomination also aims to give a unique impression at the beginning of contact with the target consumer so that it can quickly attract attention. For the back design the illustration chosen was the condition of the BING COFFEE outlet when it was busy to show the characteristics of BING COFFEE, namely the narrative cafe with a rustic design concept. Besides that, based on the request from the coachee, in the rear design, a number of words were added that were the hallmark of BING COFFEE in communicating.

f) Empty Section

Presenting a communication section with too many visual elements or information will make it look cluttered and hard to read, thereby reducing its overall effectiveness. Therefore, you should prepare a few blank parts so that the flyer does not seem dense and messy. So that the flyer does not look messy and difficult to read, then on the back of the flyer design there is an empty section filled with a cream and brown background color according to the characteristics of BING COFFEE. 


\section{Conclusion}

Based on the mapping analysis of the conditions of the BING COFFEE SMEs and the identification of problems, as well as the application of the solution of the collaboration between coaches and coachees to correct the obstacles faced by MSMEs, then it can be summarized as follows: The results of problem mapping are known that there are several aspects of the MSME store atmosphere that can be corrected. Therefore, an improvement of store atmosphere in BING COFFEE outlets has been carried out on exterior elements such as marquee, visibility, uniqueness, and general interior elements such as lighting, fixture, temperature, and dead areas.

The selection of components in each element is based on the results of discussions between the coach and the coachee to fit the concept of the booth to be made, namely narrative cafe with the concept of rustic design. After the store atmosphere improvement is carried out, the next step is to survey the customer about the appearance of the store before and after the repair to determine whether the store atmosphere improvement that has been done to improve the elements studied and the results obtained a significant increase in consumer perception of the store atmosphere after carried out implementation.

It is known in the mapping of the problem that the marketing channels used by MSMEs are still not optimal to reach the target consumers around and therefore it is done offline advertising. The implementation is carried out by interviewing the owner to determine the target consumers to be achieved and then making the design of the flyer that refers to several aspects such as keep-it-simple principle, size, type, color, illustrations, and blank parts so that the flyer is made in accordance with the discussion conducted by coaches and coaches.

\section{References}

[1] Pine II, B.J., \& Gilmore, J.H. (2011). The Experience Economy. Harvard Business Review Press.

[2] Fauzi, I. (2016). Pengaruh Store Atmosphere, Service Quality, dan Kelengkapan Produk Terhadap Purchase Intention pada SPBU Pasti Pas dan SPBU Pasti Prima Pertamina. Jurnal Magister Manajemen Universitas Indonesia. 2016.

[3] Osterwalder, A., Pigneur, Y., \& Clark, T. (2010). Business model generation : a handbook for visionaries, game changers, and challengers. Hoboken, New Jersey: Wiley, John Wiley \& Sons, Inca

[4] Thompson., Arthur A., Peteraf, Margaret A., Gamble, John E, dan Strickland III A.J. (2015). Crafting and Executing Strategy 19 th edition. Mc Graw Hill Education

[5] Muchsam, Yoki et.al. (2011), "Penerapan Gap Analysis Pada Pengembangan Sistem Pendukung Keputusan Penilaian Kinerja Karyawan (studi kasus PT. XYZ)”. Yogyakarta : Seminar Nasional Aplikasi Teknologi Informasi.

[6] Malhotra N.K. (2010). Marketing Research: An applied orientation. Sixth Edition. New Jersey: Pearson Education, Inc.

[7] Berman, Barry, and Evans, Joel R. (2018). Retail Management: A Strategic Approach, 13th edition. Upper Sadle River, New Jersey: Prentice-Hall.

[8] Ladd, A. (2010). Developing Effective Marketing Materials: Promotional Posters and Flyer Design Considerations. University of Tennessee Institute of Agriculture. 